\title{
The Electrochemical Behavior of Au/AuNPs/PNA/ZnSe-QD/ACA Electrode Towards CySH Oxidation
}

\author{
Azadeh Azadbakht • Amir Reza Abbasi · Zohreh Derikvand • Ziba Karimi
}

Received: 14 September 2014/ Accepted: 5 December 2014/Published online: 30 January 2015

(C) The Author(s) 2015. This article is published with open access at Springerlink.com

\begin{abstract}
This work describes the electrochemical behavior of azodicarboxamide (ACA) film immobilized on the surface of penicillamine (PNA)/ZnSe-quantum dot (ZnSe-QD) gold nanoparticle (AuNPs) Au electrode. Electrocatalytic activity of modified electrode toward the oxidation of cysteine ( $\mathrm{CySH})$ was investigated. The surface structure and composition of the sensor were characterized by scanning electron microscopy (SEM). Oxidation of CySH on the surface of modified electrode was investigated with cyclic voltammetry, electrochemical impedance spectroscopy (EIS), hydrodynamic voltammetry and chronoamperometry methods. The results show that the PNA/ZnSe-QD/ACA film displays excellent electrochemical catalytic activities towards $\mathrm{CySH}$ oxidation. The modified electrode shows reproducible behavior and high level of stability during the electrochemical experiments. Also it has short response time, low detection limit, high sensitivity and low operation potential, which can be used as an amperometric sensor for monitoring of $\mathrm{CySH}$. The proposed modified electrode was successfully used for determination of CySH in real sample such as human serum.
\end{abstract}

Keywords Penicillamine (PNA) - Azodicarboxamide (ACA) - ZnSe quantum dot - Electrocatalytic oxidation . Cysteine (CySH)

\section{Introduction}

Detection of biomolecules at low concentrations is critically important to the early diagnosis and successful treatment of diseases [1-3]. In addition, there have been continuous researches for fabrication of new electrode materials for developing new sensitive and selective electrochemical biosensors for the detection of the trace amounts of biomolecules [1-3]. Sulfur-containing amino acids, such as homocysteine ( $\mathrm{HCySH})$ and L-cysteine $(\mathrm{CySH})$ play crucial roles in biological systems for the diagnosis of disease states [4, 5]. CySH is known as an active site in the catalytic function of certain enzymes called CySH proteases and its deficiency is involved in

A. Azadbakht $(\bowtie) \cdot$ A. R. Abbasi · Z. Derikvand · Z. Karimi Department of Chemistry, Faculty of Science, Khorramabad Branch, Islamic Azad University, Khorramabad, Iran e-mail: azadbakht.a@gmail.com slowed growth, hair depigmentation, edema, lethargy, liver damage, muscle and fat loss, skin lesions, and weakness. It is also widely used in the food industry as an antioxidant and in the pharmaceutical industry in drug formulation [612]. Therefore, the rapid, sensitive and selective detection of $\mathrm{CysH}$ are very important for investigating their functions in cells and disease diagnosis $[13,14]$.

Numerous methods have been reported for the determination of thiols. Most of them are based on the chromatographic separation $[15,16]$, electrophoretic methods $[17,18]$ and UV/vis absorption spectrometry [14, 19, 20]. Separation methods present basic limitations in terms of equipment cost, complexity, sample processing and run times. Among different methodologies used, electrochemical measurements of thiols have attracted considerable interest because of their high sensitivity, simplicity, low cost and feasibility to the development in vivo sensors and chromatographic detectors [21, 22]. Various chemically modified electrodes (CMEs) with electrocatalytic 
properties have been fabricated and applied in the detection of CySH [23-26]. The reported CMEs have their advantages and limitations in linear dynamic range, selectivity, sensitivity, detection limit and other characteristics. As a result, it is necessary to have further efforts to fabricate simple, low cost, stable, sensitive and selective CMEs that can improve the characteristics of electrocatalytic activity for determination of $\mathrm{CySH}$.

By using nanomaterials, some of the aforementioned problems such as instability and sensitivity might be overcome. Quantum dots (QDs) are semiconductor nanocrystals that range from 2 to $10 \mathrm{~nm}$ in size. They possess size tunable optical and electronic properties. Their quantum size effects give rise to excellent electrical, optical and electrochemical properties, such as change of electrochemical potential of band edge [27]. Quantum dots have found potential applications in several areas, including catalysis, coatings, textiles, data storage, biotechnology, health care, biomedical, pharmaceutical industries, and most recently in bioanalytical chemistry [28]. When suitably functionalized with amphiphilic bifunctional molecules such as mercapto- carboxylic acids $\left[\mathrm{HS}-\left(\mathrm{CH}_{2}\right)_{\mathrm{n}^{-}}\right.$ $\mathrm{COOH}, n=1-15$ ] [29], the small sizes of quantum dots can allow for rapid transfer of electrons to the surface of the target particles, resulting to a higher charge detaching efficiency [27]. The carboxylic group also offers a convenient surface since it can react favorably with amino group of other compounds. Short chained capping agents such as mercaptopropionoc acid (MPA) and CySH have been used for self-assembly on gold electrode [30] and are associated with enhanced electrochemical signals of the quantum dots towards target analytes [31]. Azodicarboxamides $\left(\mathrm{R}_{2-}\right.$ $\mathrm{NCON}=\mathrm{NCONR}_{2}$ ) are shown to act as new templates for the assembly of unprecedented azo-functionalized hydrogen-bond-assembled [32].

In this work, we describe an electrochemical method based on azodicarboxamide (ACA) film immobilized on the surface of PNA/ZnSe-quantum dot (ZnSe-QD) gold nanoparticle (AuNPs) Au electrode for detection of $\mathrm{CySH}$. The quantum dot modifier was used to create a nanostructured/nanoscaled platform and 3-mercaptopropionic acid (3MPA) was used as the stabilizing agent to prevent the chalcogenide $\mathrm{ZnSe}$ nanocrystals from aggregating. In addition, the carboxylic acid groups of 3MPA can be used for covalent attachment of ACA via $\mathrm{N}$ hydroxysuccinimide (NHS) and 1-ethyl-3-(3-dimethylaminopropyl) carbodiimide hydrochloride (EDC) as the condensation agent. From Faraday law, current is directly proportional to the amount of the material undergoing an electrochemical reaction. These translate to changes in the rate of electron transfer or kinetics of an electrochemical reaction.

\section{Experimental}

\subsection{Chemicals}

CySH, PNA, N-hydroxysuccinimide (NHS), 1-ethyl-3-(3dimethylaminopropyl) carbodiimide hydrochloride (EDC), 3-mercaptopropionic acid (3MPA), sodium hydroxide, selenium powder, zinc nitrate, sodium citrate and $\mathrm{HAuCl}_{4}$ were purchased from Sigma-Aldrich (St. Louis, USA) and used as received. Sodium citrate, ammonia ( $25 \%)$, DMSO (99\%) and hydrochloric acid (37\%) were purchased from Merck Company (Germany) and Fluka. All other chemicals were of analytical-reagent grade and used without further purification. Double distilled water was used thoroughly. All experiments were carried out at ambient temperature of $25 \pm 1{ }^{\circ} \mathrm{C}$.

\subsection{Apparatus}

Electrochemical experiments were performed via using a $\mu$ Autolab III (Eco Chemie B.V.) potentiostat/galvanostat by NOVA 1.8 software. A conventional three-electrode cell was used with an $\mathrm{Ag} \mid \mathrm{AgCl}$ electrode $(\mathrm{KCl} 3 \mathrm{M})$ as the reference electrode, a $\mathrm{Pt}$ wire as counter electrode and a modified Au as working electrode. The cell was a onecompartment cell with an internal volume of $10 \mathrm{~mL}$. JENWAY pH-meter (model 3345) was also applied for $\mathrm{pH}$ measurements. To obtain information about the morphology and size of the particles, scanning electron microscopy (SEM) was performed using an X-30 Philips instrument.

\subsection{Synthesis of Gold Nanoparticle}

In this study, colloidal AuNPs were prepared in accordance with the literature published before [33]. Then, $0.5 \mathrm{~mL}$ of $1 \%(\mathrm{w} / \mathrm{v})$ sodium citrate solution was added to $50 \mathrm{~mL}$ of $0.01 \%(\mathrm{w} / \mathrm{v})$ of $\mathrm{HAuCl}_{4}$ boiling solution. $\mathrm{HAuCl}_{4}$ and sodium citrate aqueous solutions were filtered through a $0.22 \mu \mathrm{m}$ microporous membrane filter before use. In this procedure, all glass wares used were cleaned in freshly prepared $\mathrm{HNO}_{3} / \mathrm{HCl}$ (1:3) solution and then rinsed thoroughly with doubly distilled water. The mixture was boiled for $15 \mathrm{~min}$ and then stirred for $15 \mathrm{~min}$ after removing the heating source to produce colloidal AuNPs. The solution was stored in a refrigerator in a dark-colored glass bottle before to use. The synthesized colloidal AuNP shows maximum absorbance intensity in UV-Vis spectra at $520 \mathrm{~nm}$. If such tiny particles are allowed to coalesce, their color can be systematically varied from ruby red through violet to blue. In the current work, colloidal AuNPs were stable for 10 days and their colors remained approximately constant. 
2.4 Synthesis of 3-Mercaptopropionic Acid Capped ZnSe Quantum Dots

3MPA-ZnSe quantum dots were prepared according to method described by Andrade et al. [34] with some modification. Solution A (selenide ions) was prepared by mixing $0.16 \mathrm{~g}$ of Se powder with $0.15 \mathrm{~g}$ of $\mathrm{NaBH}_{4}$ in a round bottomed flask and adding deionized water to make $100 \mathrm{~mL}$ solution, resulting to 0.02 and $0.04 \mathrm{M}$ of $\mathrm{Se}$ and $\mathrm{NaBH}_{4}$ respectively. The mixture was then stirred continuously at room temperature under nitrogen saturation for $25 \mathrm{~min}$, after which a dark yellow solution was formed. Solution B (0.01 M zinc ions) was prepared by dissolving $0.30 \mathrm{~g}$ of zinc nitratehexahydrate in deionized water. Then $100 \mathrm{~mL}$ solution $0.696 \mu \mathrm{L}$ of 3-mercaptopropionic acid (3MPA) was added to the zinc nitrate solution, to make $0.04 \mathrm{M}$ of the capping agent in the final reaction volume $(200 \mathrm{~mL})$. The $\mathrm{pH}$ of the resulting solution (solution $\mathrm{B}$ ) was adjusted using $\mathrm{NaOH}$ and saturated with nitrogen gas for $30 \mathrm{~min}$. One hundred milliliter of the freshly prepared solution A was added drop wise into the nitrogen saturated solution B. After $40 \mathrm{~min}$, a pale yellow solution was formed. The reaction was then quenched by immediately moving the reaction flask into a freezer at $-20{ }^{\circ} \mathrm{C}$ after the $40 \mathrm{~min}$.

\subsection{Electrode Modification}

Cysteine has been used to immobilize AuNPs on a bulk gold electrode [33]. The working electrode was an Au disk electrode with a diameter of $3 \mathrm{~mm}$. Prior to each treatment, the $\mathrm{Au}$ working electrode (Metrohm) was polished with alumina slurry down to $0.05 \mathrm{~mm}$ on a polishing cloth followed by sonication in distilled water and absolute ethanol. Then the Au electrode was electrochemically cleaned by cycling the electrode potential between -0.4 and $1.2 \mathrm{~V}$ versus $\mathrm{Ag} \mid \mathrm{AgCl}$ electrode in $0.5 \mathrm{M} \mathrm{H}_{2} \mathrm{SO}_{4}$ at a scan rate of $100 \mathrm{mV} \mathrm{s}^{-1}$ until the cyclic voltammetry characteristics for a clean Au electrode were obtained. Then the clean gold electrode was immersed in aqueous solution containing $0.1 \mathrm{M} \mathrm{CySH}$ for $2 \mathrm{~h}$ at room temperature and darkness. Upon removal from the deposition solution, the substrate was thoroughly rinsed and soaked in distilled water for $12 \mathrm{~h}$ to remove the physically adsorbed $\mathrm{CySH}$ from the electrode surface. After that, it was dipped into AuNPs colloidal solution for $24 \mathrm{~h}$, in order to immobilize the AuNPs on the modified surface separately and behave as nanoelectrode array. The resultant electrode was washed with water and used for electrochemical measurements (labeled as Au/AuNPs). The Au/AuNPs electrode was immersed in the solution containing $0.1 \mathrm{M}$ PNA) for $2 \mathrm{~h}$ at room temperature and darkness (Au/AuNPs/PNA). Then the Au/AuNPs/PNA modified electrode was immersed into solution containing ZnSe-QDs $(\mathrm{pH} 7.4)$ in presence of
$0.1 \mathrm{M}$ EDC for $5 \mathrm{~h}$ to form Au/AuNPs/PNA/ZnSe-QD electrode. The resulting quantum dot modified gold electrode was allowed to dry under nitrogen gas. For ACA immobilization, Au/AuNPs/PNA/ZnSe-QD electrode was incubated for $3 \mathrm{~h}$ in a $0.1 \mathrm{M}$ phosphate buffer solution (PBS, $\mathrm{pH}$ 6.0) containing $0.5 \mathrm{mg} \mathrm{mL}^{-1}$ solution of ACA in presence of $0.1 \mathrm{M} \mathrm{EDC}$ and NHS at $4{ }^{\circ} \mathrm{C}$ (the electrode denoted as $\mathrm{Au} / \mathrm{AuNPs} / \mathrm{PNA} / \mathrm{ZnSe}-\mathrm{QD} / \mathrm{ACA})$. ACA was immobilized on the Au/AuNPs/PNA/ZnSe-QD modified electrode surface by the amide bond formation between the activated EDC and NHS treated carboxylic acid groups of the film and the amine groups on the ACA as demonstrated in Scheme 1.

For comparison, the modification of Au/AuNPs/PNA/ ZnSe-QD with ACA was also carried out by electrodeposition of ACA at the surface of electrode. For this purpose, ACA was immobilized at the surface of modified electrode by immersion Au/AuNPs/PNA/ZnSe-QD in solution containing $0.5 \mathrm{mg} \mathrm{mL}^{-1} \mathrm{ACA}$. Then the electrode potential was cycled between -0.3 and $0.3 \mathrm{~V}$ at a scan rate of $50 \mathrm{mV} \mathrm{s}^{-1}$ for 50 cycles. The result indicated that there is a considerable enhancement in the charge of voltammogram when the electrode position of ACA at the surface of $\mathrm{Au} / \mathrm{AuNPs} / \mathrm{PNA} / \mathrm{ZnSe}-\mathrm{QD}$ was occurred compared with the amide bond formation in the first case. This behavior may be attributed to saturation of active site of 3-mercaptopropionic acid in the film with the amide bond formation between the carboxylic acid groups of the 3MPA acid and the amine groups on the ACA.

To investigate the role of AuNPs, the modification of $\mathrm{Au}$ electrode was also carried out by immersion of gold electrode directly in the solution containing $0.1 \mathrm{M}$ PNA and then $\mathrm{ZnSe}-\mathrm{QD}$ in presence of $0.1 \mathrm{M}$ EDC to form Au/PNA/ $\mathrm{ZnSe}-\mathrm{QD}$ electrode. Furthermore, the role of $\mathrm{ZnSe}-\mathrm{QD}$ investigation was carried out by immersion of Au electrode in the solution containing $0.1 \mathrm{M} \mathrm{CySH}$ for $2 \mathrm{~h}$ and then into AuNPs colloidal solution for $24 \mathrm{~h}$. At last, the surface of $\mathrm{Au} / \mathrm{PNA} / \mathrm{ZnSe}-\mathrm{QD}$ and Au/AuNPs were modified by electrode position of ACA on the surface using the foregoing procedure (the electrodes denoted as $\mathrm{Au} / \mathrm{PNA} / \mathrm{ZnSe}$ QD/ACA and Au/AuNPs/ACA). The other used electrode (Au/ACA) was prepared by electrode position of ACA on the surface of bare $\mathrm{Au}$ electrode as described above.

\section{Results and Discussion}

\subsection{Characterization of the Au/AuNPs/PNA/ZnSe-QD/ ACA Electrode by SEM}

To investigate the surface structure and morphology of the modified electrode, we performed SEM. Figure 1 shows the SEM images of bare Au (Fig. 1a) and other modified electrodes. The formation of AuNPs layer on the electrode 

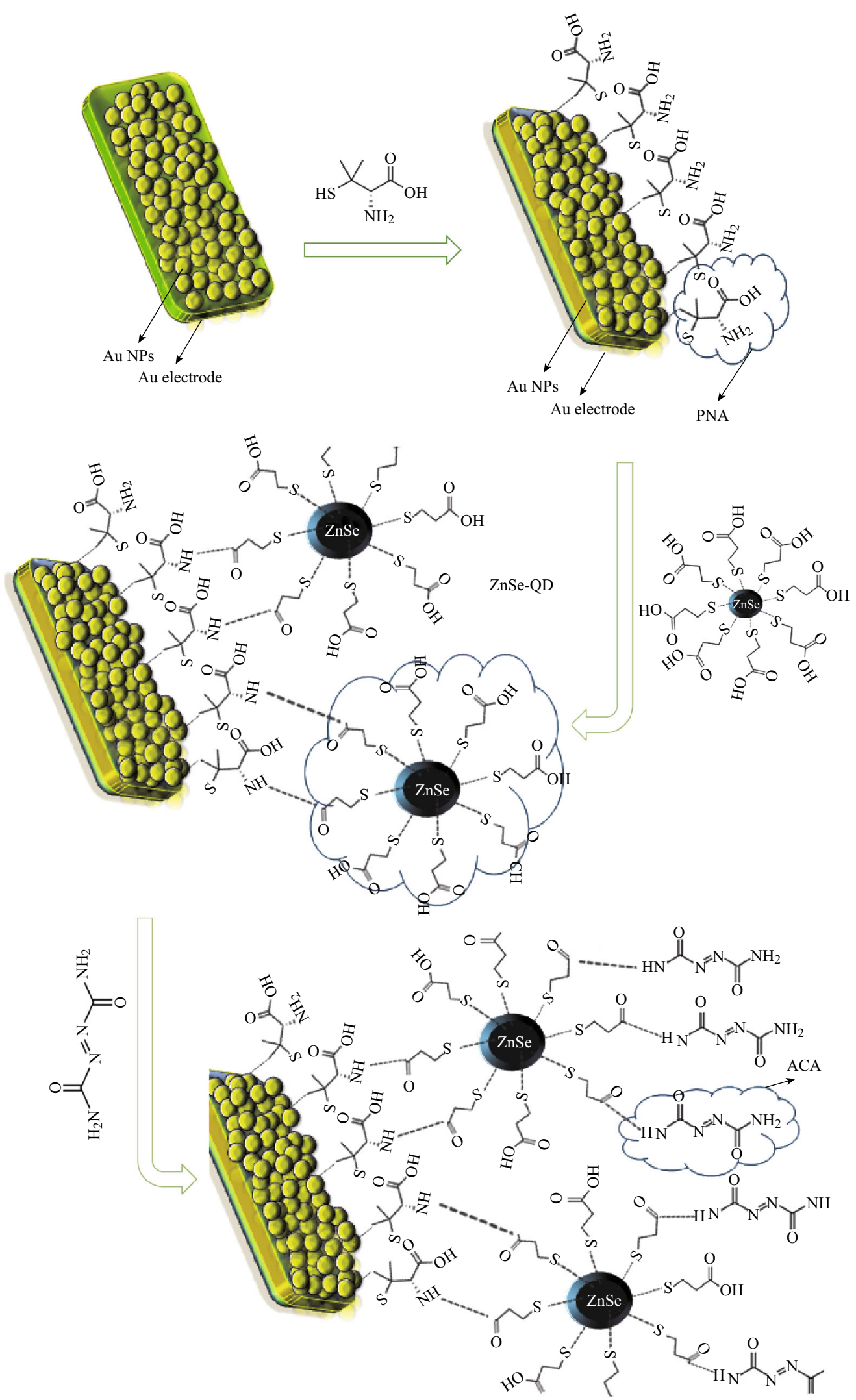

Scheme 1 Overall preparative process of the Au/AuNPs/PNA/ZnSe-QD/ACA electrode 
surface testified by SEM is shown in Fig. 1b. It can be seen that a uniform film of AuNPs immobilized onto the electrode surface. The SEM image of Au/AuNPs/PNA/ZnSe-QD modified electrode is shown in Fig. 1c in which the morphology of the electrode surface is obviously changed by the amide bond formation between the activated EDC and NHS treated carboxylic acid groups on the 3MPA/ZnSe-QD and the amine groups of the film (PNA) [35]. Figure 1d provides the SEM image of Au/AuNPs/PNA/ZnSe-QD/ACA electrode. As can be seen the generated ACA nanoparticles were homogenously distributed in the matrix of $\mathrm{ZnSe}-\mathrm{QD}$. The results indicate that the film has a globular structure with relatively homogeneous distribution. The presence of smaller nanoparticles leads to an increase in the surface coverage for adsorption of more $\mathrm{CySH}$. This structure indicates that $\mathrm{CySH}$ can penetrate through the deposit and access the underlying layer, and therefore it can be fully utilized.

\subsection{Electrochemical Behavior of Au/AuNPs/PNA/ ZnSe-QD/ACA Electrode}

The cyclic voltammograms of the ACA immobilized at the surface of Au, Au/AuNPs, Au/AuNPs/PNA and Au/AuNPs/PNA/ZnSe-QD in 0.1 M PBS (pH 6.0) at a scan rate of $50 \mathrm{mV} \mathrm{s}^{-1}$ was examined. As can be seen in Fig. 2, a pair of ill redox peaks were observed when Au/ACA (curve a) was used. Comparison of these results with that obtained with $\mathrm{Au} / \mathrm{AuNPs} / \mathrm{ACA}$ (curve c) reveals the role of AuNPs as the underlying film, which increases the peak current. This may be due to increasing the surface area of the electrode. Modification of the Au/AuNPs electrode with PNA (Au/AuNPs/PNA/ACA) decreases the electrode response (curve b) and shifted the redox peak potentials towards positive values. This may be attributed to the increase of path length of electron transfer between redox center and the surface of the bare electrode. Despite this, presences of the PNA in the modified electrode not only stabilize the QD nanoparticle, but also have the advantages of very uniform distribution of nanometer sized particles.

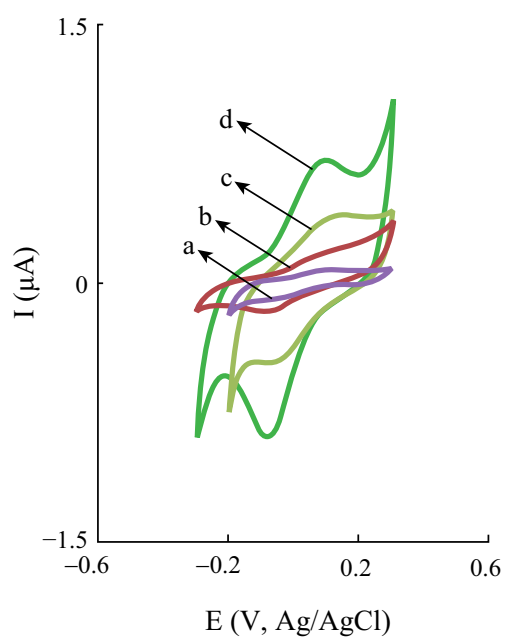

Fig. 2 Cyclic voltammograms of Au/ACA (curve a), Au/AuNPs/ PNA/ACA (curve b), Au/AuNPs/ACA (curve c) and Au/AuNPs/ $\mathrm{PNA} / \mathrm{ZnSe}-\mathrm{QD} / \mathrm{ACA}$ (curve $d$ ) in $0.1 \mathrm{M} \mathrm{PBS}(\mathrm{pH}$ 6.0) at a scan rate of $50 \mathrm{mV} \mathrm{s}^{-1}$

In order to enhance the surface area of the Au/AuNPs/ PNA/ACA electrode and its sensitivity for monitoring the analysts, improvement of the mentioned electrode was carried out. For this purpose, $\mathrm{ZnSe}-\mathrm{QD}$ was used (Au/ AuNPs/PNA/ZnSe-QD/ACA) and its CV was recorded and compared with those obtained with other tested electrodes (curve d). As it is seen from Fig. 2, the electrode improves the reversibility of the electrodic process (peaks potential separation was decreased to $110 \mathrm{mV}\left(E_{\mathrm{pa}}=0.052\right.$ and $\left.E_{\mathrm{Pc}}=-0.058\right)$. Also, its peak currents increase 2 times higher than that obtained with the Au/AuNPs/PNA/ACA electrode. The generated ZnSe-QD was homogenously distributed along the PNA, constructing individual elements of the electrode [36].

Electrochemical impedance spectroscopy (EIS) technique has been proved to be an effective method for probing the features of surface modified electrodes. Figure 3 shows the typical Nyquest plots for bare $\mathrm{Au}, \mathrm{Au} /$ AuNPs, Au/AuNPs/PNA, Au/AuNPs/PNA/ZnSe-QD and
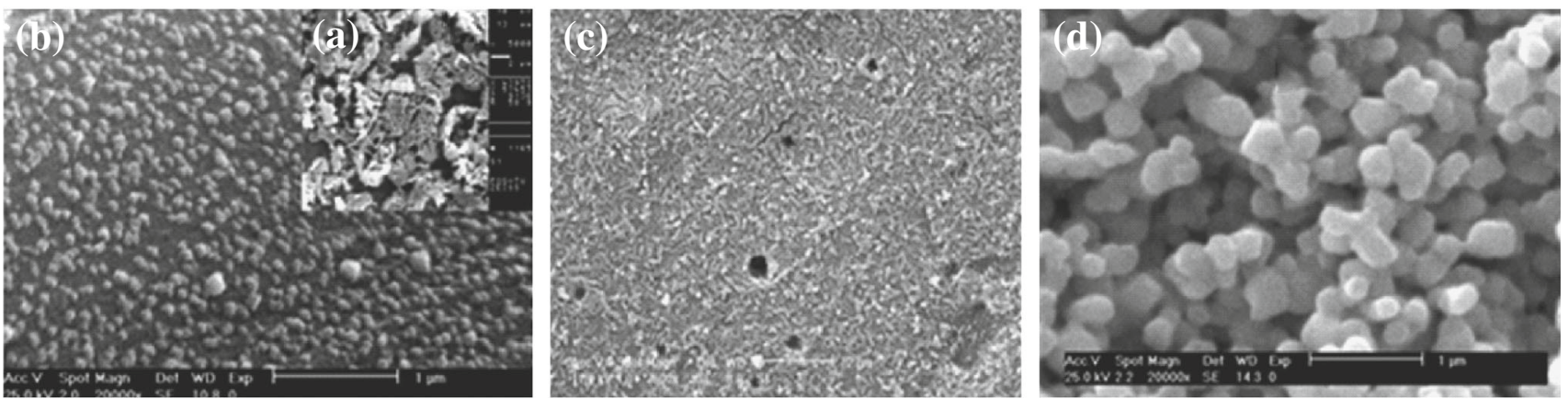

Fig. 1 Typical SEM images of various electrodes: a bare Au bare, b Au/AuNPs, c Au/AuNPs/PNA/ZnSe-QD, and d Au/AuNPs/PNA/ZnSe-QD/ ACA 
$\mathrm{Au} / \mathrm{AuNPs} / \mathrm{PNA} / \mathrm{ZnSe}-\mathrm{QD} / \mathrm{ACA}$ electrodes recorded in $0.1 \mathrm{M} \mathrm{KCl}$ solution containing $0.5 \mathrm{mM} \mathrm{Fe}(\mathrm{CN})_{6}^{3-/ 4-}$ as an electrochemical redox marker. The straight line at low frequency is related to the diffusion process known as Warburg element, while the high frequency semicircle is related to $R_{e t}$ which controls the electron transfer kinetics of the redox probe at the electrode interface [13]. The EIS at a bare Au electrode displays a very small semicircle and the charge transfer resistance, which was a characteristic feature of the diffusion controlled electrochemical processes (Fig. 3a). After modification of Au electrode with AuNPs, $R_{c t}$ decreased and it can be seen that an almost straight line is exhibited. This behavior proved that the assembly of AuNPs makes the electron transfer easier (Fig. 3b). After immobilization of PNA, the value of $R_{e t}$ is significantly increased to about $520 \Omega$. It indicates hindrance to the electron transfer, confirming the successful immobilization of PNA onto Au/AuNPs electrode surface (Fig. 3c). Subsequently, when the Au/AuNPs/PNA electrode was modified with $\mathrm{ZnSe}-\mathrm{QD}$ layer, $R_{e t}$ increased to $982 \Omega$ (Fig. 3d), suggesting that the semiconductor film was successfully immobilized on the electrode surface. The observed increase can be attributed to the electrostatic repulsion between $\left[\mathrm{Fe}(\mathrm{CN})_{6}\right]^{3-14-}$ redox marker and $\mathrm{SCH}_{2}\left(\mathrm{CH}_{2}\right) \mathrm{COO}^{-}$complexes. For the $\mathrm{Au} / \mathrm{AuNPs} / \mathrm{PNA} /$ $\mathrm{ZnSe}-\mathrm{QD} / \mathrm{ACA}$ modified electrode, the $R_{e t}$ decreased to $418 \Omega$, which confirms that the ACA complex have been successfully attached to the electrode surface and makes the electron transfer easier (Fig. 3e). These results indicate that the Au/AuNPs/PNA/ZnSe-QD/ACA electrode could provide good electron conduction pathways between the electrode and electrolyte.

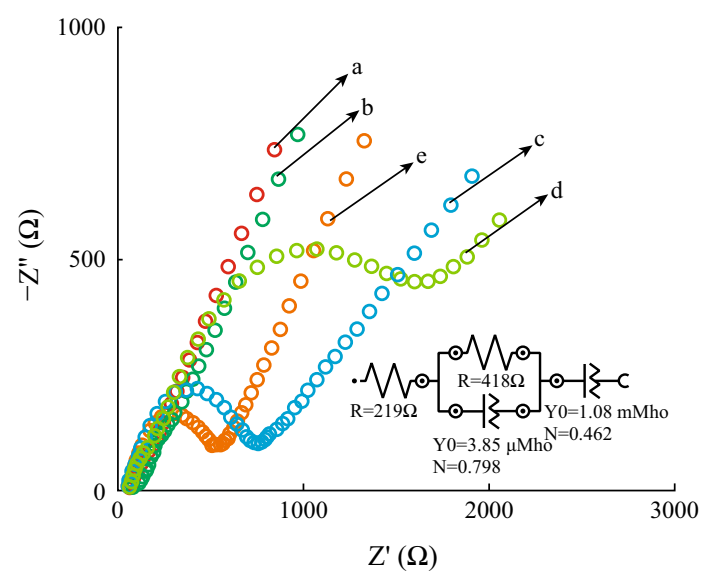

Fig. 3 Nyquest plots for bare $\mathrm{Au}$ (curve a), Au/AuNPs (curve b), Au/ AuNPs/PNA (curve c), Au/AuNPs/PNA/ZnSe-QD (curve d) and Au/ AuNPs/PNA/ZnSe-QD/ACA (curve e) electrodes recorded in $0.1 \mathrm{M}$ $\mathrm{KCl}$ solution containing $0.5 \mathrm{mM} \mathrm{Fe}(\mathrm{CN})_{6}^{3-/ 4-}$ in the frequency range of $10 \mathrm{kHz}-0.1 \mathrm{~Hz}$. Inset the equivalent circuit used to fit the experimental impedance data
3.3 Properties of the Nano-structured Au/AuNPs/PNA/ ZnSe-QD/ACA Electrode

In the preliminary experiments the electrochemical behavior of ACA was studied at the surface of Au/AuNPs/ PNA/ZnSe-QD electrode using cyclic voltammetric technique. The results showed one pair of redox peaks with a formal potential of $0.03 \mathrm{~V}$ versus $\mathrm{Ag} \mid \mathrm{AgCl}$ electrode.

The effect of $\mathrm{pH}$ on the electrochemical behavior of ACA at the surface of Au/AuNPs/PNA/ZnSe-QD electrode was also studied at $\mathrm{pH}$ values ranging from 1 to 7 . A welldefined redox peaks were observed at acidic media $(\mathrm{pH}<7)$. At $\mathrm{pH}_{\mathrm{s}}$ greater than 7 , the shape and the reproducibility of redox peak were poor. The results revealed that the maximum peak current was obtained at $\mathrm{pH} 6$. The potential of the anodic peak of ACA was shifted linearly toward less positive potential values with increasing the $\mathrm{pH}$ between 1 and 7 by slope of $98 \mathrm{mV} \mathrm{pH}^{-1}$. The number of hydrogen ions participated in the rate determining step $\left(Z_{H+}\right)$ can be obtained from the slope value of the linear segment of the $E_{p}-\mathrm{pH}$ plot $\left(59 Z_{H+} /(1-\alpha) n\right)$. The slope of $98 \mathrm{mV} / \mathrm{pH}$ for ACA oxidation indicating that the number of protons involved in the reaction mechanisms is equal to number of electron precipitate in electrodic process $\left(Z_{H+} / n\right.$ $=98 \times(1-0.41) / 59=0.98) . \quad(\alpha$ was calculated from Eq. 2).

Furthermore, effect of the scan rate on the CVs of ACA was studied. From the plot of $I_{p}$ versus $v^{1 / 2}$, the number of electrons (n) involved in the overall reaction was obtained according to the following equation [37]:

$I_{\mathrm{p}}=2.99 \times 10^{5} n(1-\alpha)^{1 / 2} A C_{b} D^{1 / 2} v^{1 / 2}$

where $A$ is electrode surface area, $C_{b}$ is the ACA concentration and $D$ is the diffusion coefficient ( $D$ was calculated from chronoamperometry technique). From the slope of the $I_{\mathrm{p}}$ versus $v^{1 / 2}$ plot, the total number of electrons $(n)$ is about two. Based on the above results, a possible reaction mechanism of oxidation process is suggested as shown in Scheme 2).

Figure 4a exhibits the recorded cyclic voltammograms of Au/AuNPs/PNA/ZnSe-QD/ACA film in 0.1 M PBS ( $\mathrm{pH}$ $6)$ at different scan rates. In Fig. 4b, the plots of anodic and cathodic peak currents versus the scan rate are presented for the modified electrode. As is obvious, both the anodic and cathodic peak currents are linearly proportional to the scan rate in the range of $10-400 \mathrm{mV} \mathrm{s}^{-1},\left(R^{2}=0.998\right.$ and 0.993 for anodic and cathodic peak, respectively) indicating a surface confined electrode process. The peak-to-peak potential separation is about $100 \mathrm{mV}$ at scan rates below $50 \mathrm{mV} \mathrm{s}^{-1}$, suggesting facile charge transfer kinetics over this range of sweep rates. At higher sweep rates $\left(v>100 \mathrm{mV} \mathrm{s}^{-1}\right)$ peak separations begin to increase, 


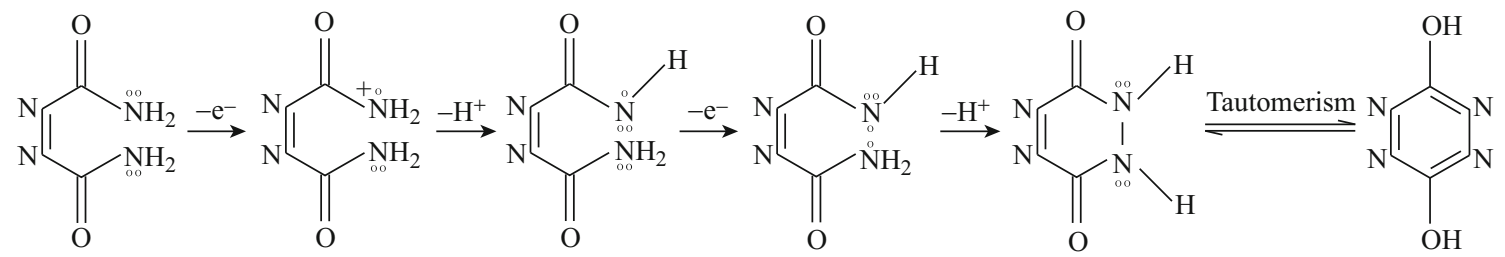

The overall electrochemical reaction is shown as follows:<smiles>NC(=O)/C=N\C(=O)N1NNC(=O)N1</smiles>

Scheme 2 Suggested mechanism for the redox peak of ACA
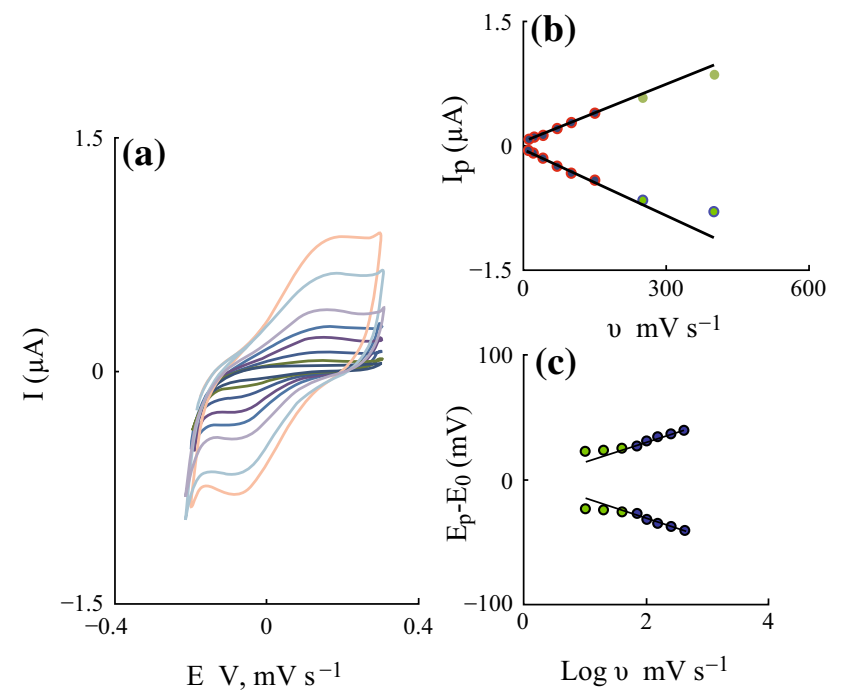

Fig. 4 a Cyclic voltammetric response of $\mathrm{Au} / \mathrm{AuNPs} / \mathrm{PNA} / \mathrm{ZnSe}$ QD/ACA modified electrode in 0.1 M PBS ( $\mathrm{pH}$ 6.0) at different scan rates; from inner to outer: $10,20,40,70,100,150,250$, and $400 \mathrm{mV} \mathrm{s}^{-1}$. b Plot of peak currents vs. scan rate. c Plot of $\left(E_{\mathrm{p}}-E^{\circ}\right)$ $(\mathrm{mV})$ versus $\log v$

indicating the limitation due to charge transfer kinetics. The shifts of peak potentials were proportional to the logarithm of the scan rate for scan rates higher than $100 \mathrm{mV} \mathrm{s}^{-1}\left(R^{2}=0.989\right.$ and 0.988 for anodic and cathodic peak, respectively) (see Fig. 4c).

Based on Laviron theory [38], the electron transfer rate constant $\left(k_{s}\right)$ and charge transfer coefficient $(\alpha)$ can be determined. By measuring the variation of peak potential with scan rate, using the following Eq. 1, the charge transfer coefficient $(\alpha)$ was determined:

$E_{\mathrm{p}}=K_{\mathrm{s}}-2.3030(R T / \alpha n F) \log v$

The slope of $\Delta E_{\mathrm{pc}}$ versus $\log v$ was about $50 \mathrm{mV}$ and the electrons transferred for ACA were 2 (from Eq. 1), and then $\alpha$ were calculated as 0.41 . By introducing $\alpha$ value in the following Eq. 3, for $\Delta E_{p} \geq 200 / n \mathrm{mV}$, the electron transfer rate constant was estimated to be $0.31 \pm 0.03 \mathrm{~s}^{-1}$.

$$
\begin{aligned}
\log k_{s}= & \alpha \log (1-\alpha)+(1-\alpha) \log \alpha-\log (R T / n F v) \\
& -\alpha \log (1-\alpha) n F \Delta E_{p} / 2.3 R T
\end{aligned}
$$

The large value obtained for $k_{s}$ indicates high ability of ZnSe-QD nanoparticles for promoting the transfer of electrons between ACA and the electrode surface. The surface coverage concentration $(\Gamma)$ of ACA was estimated by integrating the area under the cathodic peak. According to the equation $Q=\Gamma / n F A$ and assuming $A=0.12 \mathrm{~cm}^{2}$, the surface concentration of the proposed molecule was about $1.46( \pm 0.20) \times 10^{-8} \mathrm{~mol} \mathrm{~cm}{ }^{-2}$. The surface concentration value indicated the formation of multilayer of ACA on the Au/AuNPs/PNA/ZnSe-QD modified electrode and high loading ability of $\mathrm{ZnSe}-\mathrm{QD}$ nanoparticles for immobilization of ACA [39].

The long term stability of the Au/AuNPs/PNA/ZnSeQD/ACA modified electrode and the reversibility of its electrochemical behavior were also investigated. It was found that after storing the electrode in ambient condition for 1 week, the current and potential response of recorded cyclic voltammograms remained almost unchanged. In addition, the operational stability of the modified electrode was examined by recording of the repetitive cyclic voltammograms in $0.1 \mathrm{M}$ PBS (Fig. 5). The results indicated that after 100 repetitive cycles at a scan rate of $50 \mathrm{mV} \mathrm{s}^{-1}$, no detectable change was observed at the peak height and potential separation. The high stability of Au/AuNPs/PNA/ ZnSe-QD/ACA modified electrode may be related to the mechanical and chemical stability of ZnSe-QD film along with the attachment of ACA. This behavior leads to its stabilizing against desorption and avoids it from leaching into the solution. In order to study the reproducibility of the electrode modification, five Au/AuNPs/PNA/ZnSe-QD/ ACA modified electrodes were prepared independently. For five successive prepared electrodes, the relative 
standard deviation (RSD) of measuring anodic peak currents was only $5 \%$.

\subsection{Electrocatalytic Oxidation of $\mathrm{CySH}$ at $\mathrm{Au} / \mathrm{AuNPs} /$ $\mathrm{PNA} / \mathrm{ZnSe}-\mathrm{QD} / \mathrm{ACA}$ Electrode}

Application of the modified electrode for oxidation of $\mathrm{CySH}$ was evaluated by cyclic voltammetry. Oxidation of $\mathrm{CySH}$ at $\mathrm{Au} / \mathrm{AuNPs} / \mathrm{PNA} / \mathrm{ZnSe}-\mathrm{QD}$ electrode and Au/AuNPs/PNA/ $\mathrm{ZnSe}-\mathrm{QD} / \mathrm{ACA}$ electrodes were investigated in 0.1 M PBS (pH 6.0). Figure 6 shows recorded cyclic voltammograms in the absence and presence of $2 \mathrm{mM} \mathrm{CySH}$ at Au/AuNPs/ PNA/ZnSe-QD and Au/AuNPs/PNA/ZnSe-QD/ACA electrodes with scan rate of $50 \mathrm{mV} \mathrm{s}^{-1}$. As can be seen, no electrochemical response at Au/AuNPs/PNA/ZnSe-QD electrode was observed in the absence of $\mathrm{CySH}$ (voltammogram "c"), but in the presence of $\mathrm{CySH}$ a small redox response can be seen (voltammogram "d"). However, in the same conditions at $\mathrm{Au} / \mathrm{AuNPs} / \mathrm{PNA} / \mathrm{ZnSe}-\mathrm{QD} / \mathrm{ACA}$ electrode, the oxidation current of $\mathrm{CySH}$ starts at $-0.15 \mathrm{~V}$ and an obvious catalytic oxidation peak appears at the potential of $0.05 \mathrm{~V}$ (voltammogram "b"). It can be seen that peak potential for oxidation of $\mathrm{CySH}$ is significantly shifted to a more negative potential $(0.05 \mathrm{~V}$ vs. $\mathrm{Ag} \mid \mathrm{AgCl})$ compared with Au/AuNPs/PNA/ZnSe-QD modified electrode $(0.55 \mathrm{~V}$ vs. $\mathrm{Ag} \mid \mathrm{AgCl})$. Furthermore, the anodic peak current was greatly enhanced in the presence of $\mathrm{CySH}$ and the reduction peak current totally disappeared, suggesting a typical electrocatalytic oxidation process. The substantially decreasing overvoltage and increasing oxidation peak current of $\mathrm{CySH}$ confirm that ACA immobilized onto Au/AuNPs/PNA/ZnSeQD electrode can act as an efficient mediator to shuttle electrons between $\mathrm{CySH}$ and working electrode.

To understand the undergoing electrochemical reactions at the different modified electrodes, the EIS experiments

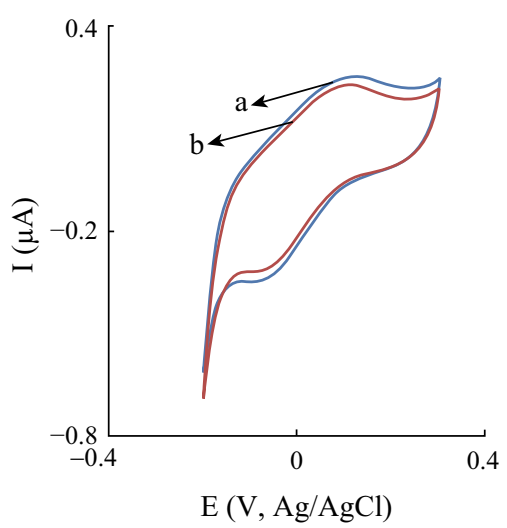

Fig. 5 The first $(a)$ and 100th $(b)$ cyclic voltammograms of $\mathrm{Au} /$ AuNPs/PNA/ZnSe-QD/ACA modified electrode in 0.1 M PBS (pH 6.0) at scan rate of $50 \mathrm{mV} \mathrm{s}^{-1}$

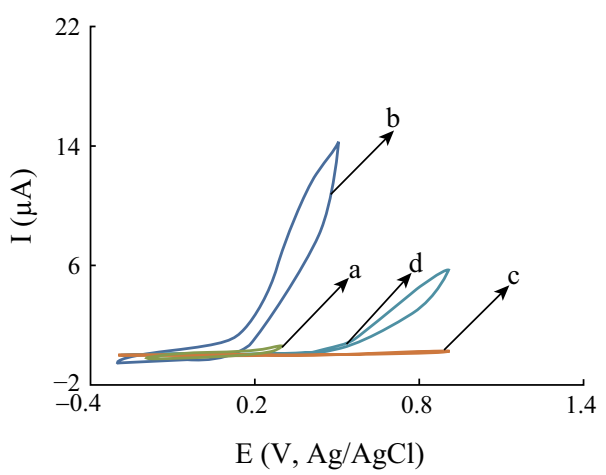

Fig. 6 Cyclic voltammograms of Au/AuNPs/PNA/ZnSe-QD/ACA (curves $a$ and $b$ ) and Au/AuNPs/PNA/ZnSe-QD (curves $c$ and $d$ ) electrodes in the absence (curves $a$ and $c$ ) and presence (curves $b$ and $d$ ) of $2 \mathrm{mM}$ of CySH in $0.1 \mathrm{M}$ PBS (pH 6.0) at scan rate of $50 \mathrm{mV} \mathrm{s}^{-1}$

were performed in the presence of $4 \mathrm{mM}$ of $\mathrm{CySH}$ in $0.1 \mathrm{M}$ PBS ( $\mathrm{pH}$ 6.0). As can be seen in Fig. 7 for Au electrode, a semicircle curve was observed over the whole frequency region and the value of $R_{e t}$ is $1,100 \Omega$, indicating that the reaction is kinetically controlled (Fig. 7a). After immobilization of ACA at the surface of gold electrode, the value of $R_{e t}$ was significantly decreased to about $120 \Omega$ (Fig. 7b). These results indicate that the immobilized ACA increases the charge transfer kinetics to about one-ninth of that at the bare Au electrode. It also confirmed that presence of ACA film on $\mathrm{Au}$ electrode had a catalytic effect for oxidation of CySH. For Au/PNA/ZnSe-QD/ACA (Fig. 7c) and Au/ AuNPs/PNA/ZnSe-QD/ACA (Fig. 7d) the calculated charge transfer resistance are decreased, which proves that the assembly of AuNPs nanoparticles and ZnSe-QD makes the electron transfer easier. The deposition of AuNPs and $\mathrm{ZnSe}-\mathrm{QD}$ on the surface of modified electrode facilitates the electron transfer of the electrochemical probe on the modified electrode.

For further investigation of the electrocatalytic properties of different modified electrodes, cyclic voltammograms of these electrodes in the presence of $\mathrm{CySH}$ at a wide potential range were recorded. The cyclic voltammetric responses of $\mathrm{Au} / \mathrm{AuNPs} / \mathrm{PNA} / \mathrm{ZnSe}-\mathrm{QD} / \mathrm{ACA}, \mathrm{Au} /$ AuNPs/ACA, Au/PNA/ZnSe-QD/ACA, Au/ACA, and Au/ AuNPs electrodes in $0.1 \mathrm{M}$ PBS in the absence and presence of $5 \mathrm{mM} \mathrm{CySH}$ were recorded. $\mathrm{CySH}$ did not undergo oxidation at $\mathrm{Au} / \mathrm{AuNPs}$ electrode in the potential window of $-0.4-0.4 \mathrm{~V}$ in $0.1 \mathrm{M}$ PBS and a pair of ill redox peaks were observed when Au/ACA was used. However, presence of ACA film on Au/AuNPs electrode had a catalytic effect for oxidation of $\mathrm{CySH}$. The result shows that in the absence of $\mathrm{CySH}$ a pair of redox peaks corresponding to the $(\mathrm{ACA})_{\mathrm{ox}} /(\mathrm{ACA})_{\mathrm{R}}$ couple were observed at the surface of the electrodes tested. Upon addition of $\mathrm{CySH}$, an enhancement in the anodic peak 


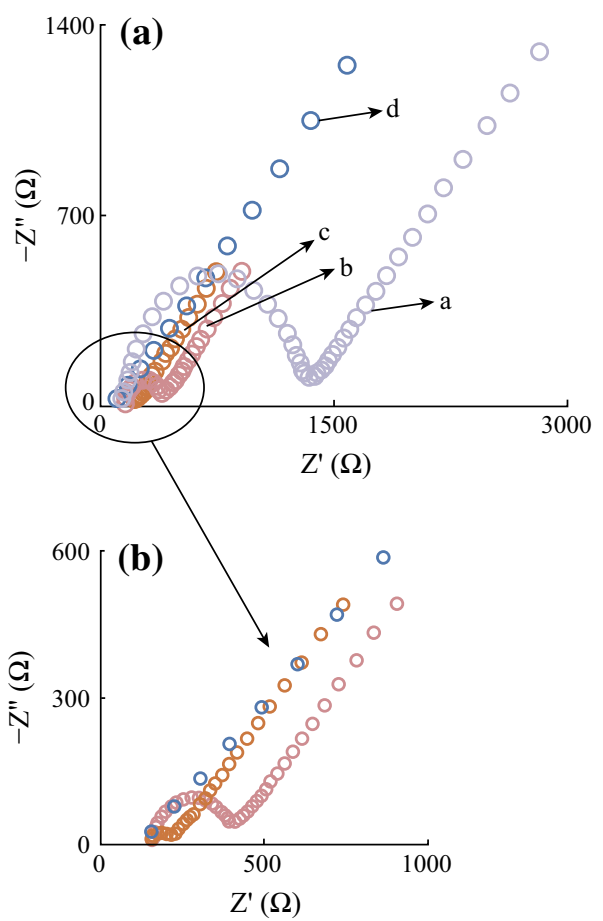

Fig. 7 Nyquist plots of bare Au electrode (curve a), Au/ACA (curve $b$ ), $\mathrm{Au} / \mathrm{PNA} / \mathrm{ZnSe}-\mathrm{QD} / \mathrm{ACA}$ (curve $c$ ) and Au/AuNPs/PNA/ZnSeQD/ACA (curve d) in $0.1 \mathrm{M}$ in PBS containing $4 \mathrm{mM}$ CySH in the frequency range of $10 \mathrm{kHz}-0.1 \mathrm{~Hz}$

current was observed and the cathodic peak current tended to decrease. The reason for this increase is that, along with the anodic potential sweep, $\mathrm{CySH}$ reduces $(\mathrm{ACA})_{\mathrm{ox}}$ to $(\mathrm{ACA})_{\mathrm{R}}$. Simultaneous oxidation of the regenerated $(\mathrm{ACA})_{\mathrm{R}}$ causes an increase in the anodic current. For the same reason, the cathodic current is smaller in the presence of $\mathrm{CySH}$ indicating that (ACA) $)_{\mathrm{ox}}$ is consumed during a chemical step. Moreover, the electrocatalytic oxidation peak current of $\mathrm{CySH}$ at $\mathrm{Au} / \mathrm{AuNPs} / \mathrm{PNA} / \mathrm{ZnSe}-\mathrm{QD} / \mathrm{ACA}$ electrode is $12 \mu \mathrm{A}$, which is 1.7 times larger than that at $\mathrm{Au} / \mathrm{AuNPs} / \mathrm{ACA}$ electrode $(7 \mu \mathrm{A})$ and 2.1 times larger than that at $\mathrm{Au} / \mathrm{PNA} / \mathrm{ZnSe}-\mathrm{QD} / \mathrm{ACA}$ electrode. This behavior is in agreement with EIS data for charge transfer kinetics on the different modified electrodes. These results indicate that presence of $\mathrm{ZnSe}-\mathrm{QD}$ and AuNPs in the modified electrode supplied a larger surface area to allow more deposition of ACA complex for oxidation of $\mathrm{CySH}$.

Cyclic voltammograms of different concentrations of $\mathrm{CySH}$ (ranging from 0.5 to $90 \mathrm{mM}$ ) at the modified electrode in $0.1 \mathrm{M}$ PBS were recorded. The calibration curve based on the anodic peak current is linear with the $\mathrm{CySH}$ concentration in the range of $0.5-35 \mathrm{mM}$ with a correlation coefficient of 0.996 (Fig. 8b, blue symbols). The response of modified electrode was deviated from the linearity for CySH concentration above $35 \mathrm{mM}$ (Fig. 8b, red symbols). This behavior may be attributed to saturation of some redox sites on the surface of electrode, which are involved in the catalytic reaction. As can be seen from Fig. 8a-c (magnification at low concentration) by increasing the concentration of $\mathrm{CySH}$, the anodic peak current of the modified electrode is increased while its cathodic peak current decreased, indicating a typical electrocatalytic oxidation process $\left(\mathrm{EC}^{\prime}\right)$.

For investigation the electrocatalytic mechanism of the modified electrode toward $\mathrm{CySH}$ oxidation, cyclic voltammograms of modified electrode in $5 \mathrm{mM}$ CySH containing 0.1 M PBS ( $\mathrm{pH}$ 6.0) at different scan rates were recorded. Figure 9a illustrates cyclic voltammograms of $5 \mathrm{mM}$ CySH using modified electrode at potential sweep rates ranging from 10 to $150 \mathrm{mV} \mathrm{s}^{-1}$.

The anodic peak currents obtained were linear with respect to the square root of the potential sweep rate $\left(R^{2}=0.997\right)$ (Fig. 9b), which indicates the mass transfer controlled process. Also, it can be seen that the anodic peak potential shifts toward positive potentials by increasing the scan rate. This behavior suggests a kinetic limitation in the reaction between redox sites of the Au/AuNPs/PNA/ZnSe$\mathrm{QD} / \mathrm{ACA}$ electrode and CySH. The $\alpha$ value of the electrodic reaction can be evaluated from the following equation [40]:

$E_{\mathrm{p}}=(b / 2) \log v+$ constants

On the basic of Eq. 4, the slope of $E_{\mathrm{p}}$ versus $\log v$ plot is $b / 2$, where $\mathrm{b}$ indicates the Tafel slope $\left(b=2.3 R T / n_{\alpha} F(1-\right.$ $\alpha)$ ). The plot of $E_{\mathrm{p}}$ versus $\log v$ indicates a linear variation for scan rates ranging $10-150 \mathrm{mV} \mathrm{s}^{-1}$ (Fig. 9c). The slope is $\partial E_{\mathrm{p}} / \partial \log v$, which was found to be $0.0315 \mathrm{~V}$ with correlation coefficient of 0.994 . So, $b=2 \times 0.0315=$ $0.063 \mathrm{~V}$. Assuming that the number of electrons transferred in the rate limiting step is equal to 2 , a transfer coefficient of $\alpha$ was estimated as 0.53 . Taking into account all these

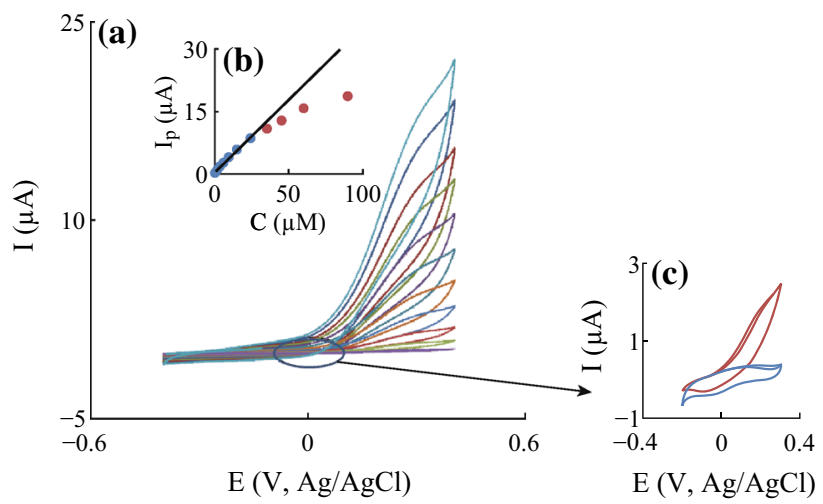

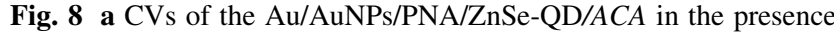
of different CySH concentration: 0.5, 1, 3, 5, 9, 15, 24, 35, 45, 60, and $90 \mathrm{mM}$ respectively in $0.1 \mathrm{M}$ in PBS at a scan rate of $50 \mathrm{mV} \mathrm{s}^{-1}$. b Inset the plot of catalytic peak versus $\mathrm{CySH}$ concentration, c the detailed magnified region 


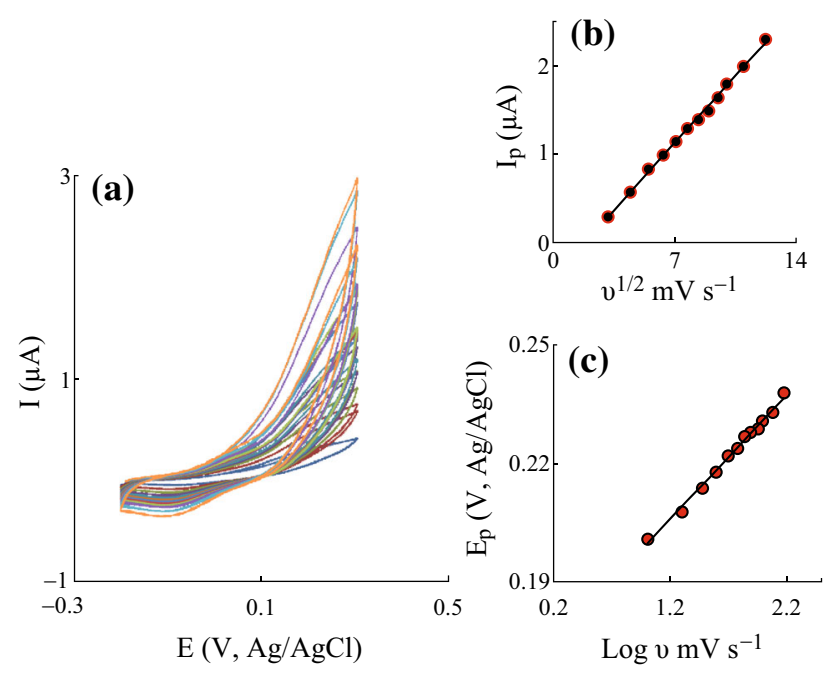

Fig. 9 a Cyclic voltammograms of the modified electrode in the presence of $5 \mathrm{mM} \mathrm{CySH}$ at various scan rates: 10, 20, 40, 70, 100, 150,250 , and $400 \mathrm{mV} \mathrm{s}^{-1}$ in $0.1 \mathrm{M}$ in PBS. b Variation of anodic peak currents versus square root of potential scan rate, $\mathbf{c}$ dependence of the anodic peak potential versus logv

observations, a possible mechanism of CySH electrooxidation on Au/AuNPs/PNA/ZnSe-QD/ACA electrode may be as follows:

$\mathrm{CySH} \leftrightarrow \mathrm{CyS}^{-}+\mathrm{H}^{+}$<smiles>NC(=O)N=NC(N)=O</smiles><smiles></smiles><smiles></smiles><smiles>NC(=O)/N=N\C(N)=O</smiles>

$$
2 \mathrm{Cys}^{\bullet} \rightarrow \mathrm{CySSCy}
$$

This is similar to the mechanism reported previously for CySH oxidation on solid electrodes [41]. For CySH oxidation at the surface of Au/AuNPs/PNA/ZnSe-QD (Fig. 6 curve d) a possible mechanism may be as follows [26]:

$$
\begin{aligned}
& \mathrm{CySH} \leftrightarrow \mathrm{CyS}^{-} \\
& \mathrm{Cys}^{-} \rightarrow \mathrm{CyS}^{\cdot}+\mathrm{e}^{-} \\
& 2 \mathrm{CyS}^{-} \rightarrow \mathrm{CySSCy}
\end{aligned}
$$

\subsection{Chronoamperometric Studies}

The chronoamperometry (CA) method, as well as other electrochemical methods was employed for the investigation of electrode processes at chemically modified electrodes. The result shows a series of well-defined chronoamperograms for the Au/AuNPs/PNA/ZnSe-QD/ ACA in the absence and presence of different concentrations of $\mathrm{CySH}$ at an applied potential of 0.05 versus $\mathrm{Ag} \mid \mathrm{AgCl}$. For an electroactive material with diffusion coefficient of $D$, the corresponding current of the electrochemical reaction (under diffusion control) is described by Cottrell's law [39]:

$I=n F A D^{1 / 2} C_{0} \pi^{-1 / 2} t^{-1 / 2}$

where $D$ and $C_{0}$ are the diffusion coefficient and bulk concentration, respectively. The average value of $D$ obtained from the slopes of $I$ versus $t^{-1 / 2}$ plots for different concentrations of CySH is $1.21 \times 10^{-6} \mathrm{~cm}^{2} \mathrm{~s}^{-1}$. Chronoamperometry can be used for the evaluation of the catalytic rate constant. At intermediate times, the catalytic current $\left(I_{\text {cat }}\right)$ is dominated by the rate of electrocatalyzed oxidation of $\mathrm{CySH}$. The rate constant for the chemical reaction between $\mathrm{CySH}$ and redox sites was determined according to the method described in the literature [42]:

$I_{\text {cat }} / I_{L}=\left[\gamma^{1 / 2}\left[\pi^{1 / 2} \operatorname{erf}\left(\gamma^{1 / 2}\right)+\exp (-\gamma) / \gamma^{1 / 2}\right]\right.$.

where $I_{\text {cat }}$ and $I_{L}$ are the currents of the Au/AuNPs/PNA/ $\mathrm{ZnSe}-\mathrm{QD} / \mathrm{ACA}$ electrode in the presence and absence of $\mathrm{CySH}$, and $\gamma=k C_{0} t$ is the dimensionless kinetic parameter, $k$ is the catalytic rate constant, $C_{0}$ is the bulk concentration of $\mathrm{CySH}$, erf is error function and $t$ is the elapsed time. In such cases where $\gamma>2$, erf $\left(\gamma^{1 / 2}\right)$ is almost equal to unity. The above equation can be reduced to:

$I_{\text {cat }} / I_{L}=\gamma^{1 / 2} \pi^{1 / 2}=\pi^{1 / 2}\left(k C_{0} t\right)^{1 / 2}$

From the slope of the $I_{\text {cat }} / I_{L}$ versus $t^{1 / 2}$ plot, the average value of $k_{\text {cat }}$ was found to $4.25 \times 10^{2} \mathrm{M}^{-1} \mathrm{~s}^{-1}$.

\subsection{Amperometric Detection of $\mathrm{CySH}$ at the Modified Electrode}

Since amperometry under stirred conditions has a much higher current sensitivity than cyclic voltammetry, it was used to estimate the lower limit of detection. Figure 10a shows a typical steady-state catalytic current time response of the rotating modified electrode $(2,000 \mathrm{rpm})$ with successive injection of $1 \mu \mathrm{M}$ of $\mathrm{CySH}$ at an applied potential of $0.05 \mathrm{~V}$ versus the reference electrode.

As shown, during the successive addition of CySH a well-defined response was observed, demonstrating stable and efficient catalytic ability of the AuNPs/PNA/ZnSe-QD/ 


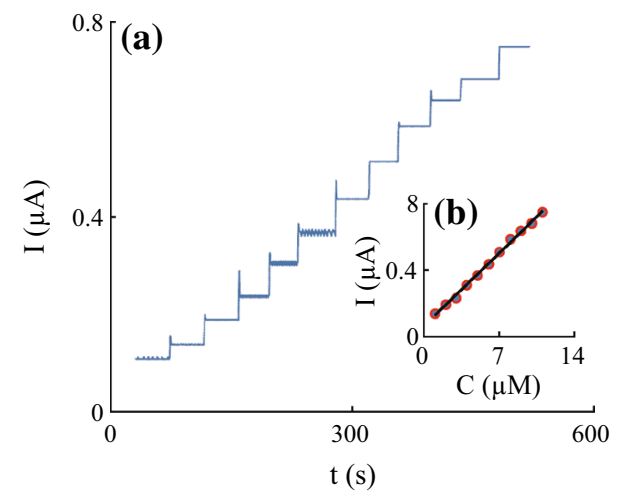

Fig. 10 a Amperometric response of rotating sensor during $\mathrm{CySH}$ addition (potential $=0.05 \mathrm{~V}, \mathrm{pH} 6$, and rotation speed of 2,000 rpm, successive addition of $1 \mu \mathrm{M} \mathrm{CySH}$ ). b Plots of current versus $\mathrm{CySH}$ concentration

ACA film immobilized the surface of electrode. The calibration plot over the concentration range of $1-11 \mu \mathrm{M}(11$ points) is linear with a correlation coefficient of 0.9994 and the detection limit of $0.04 \mu \mathrm{M}$ at the signal to noise ratio of 3. Detection limit and linear calibration range of the proposed method were compared with those obtained in other reports and the results are summarized in Table 1. Although the linear range of the proposed modified electrode is smaller than those reported in some previous works its detection limit is comparable or better than the results reported for $\mathrm{CySH}$ determination at the surface of recently fabricated modified electrodes [25, 43-51].

\subsection{Application of Electrochemical Sensor for Determination of CySH in Human Serum Samples}

To demonstrate the application of the CySH electrochemical sensor, CySH concentrations in real samples were measured. A serum sample of a healthy volunteer was stored frozen
Table 2 Determination of L-cysteine in human serum samples $(\%$, \pm RSD calculated \& based on five measurements)

\begin{tabular}{lllr}
\hline Sample & Added $(\mu \mathrm{M})$ & Found $(\mu \mathrm{M})$ & Recovery $(\%)$ \\
\hline Serum sample 1 & - & $205.0 \pm 4.0$ & \\
& 20.0 & $224.0 \pm 5.0$ & $99.5 \pm 2.0$ \\
& 60.0 & $269.6 \pm 4.0$ & $101.5 \pm 1.5$ \\
Serum sample 2 & - & $200.5 \pm 4.0$ & \\
& 20.0 & $222.5 \pm 4.0$ & $100.9 \pm 2.0$ \\
& 60.0 & $253.5 \pm 4.5$ & $97.5 \pm 1.5$ \\
\hline
\end{tabular}

until assay. $2 \mathrm{~mL}$ of methanol was added to $1.5 \mathrm{~mL}$ of serum sample. After vortexing the serum sample for $2 \mathrm{~min}$, the precipitated proteins were separated by centrifugation for $3 \mathrm{~min}$ at $6,000 \mathrm{rpm}$. The clear supernatant layer was filtered to obtain protein free human serum sample and its volume was adjusted to $150 \mathrm{~mL}$ using double distilled water, then $15 \mathrm{~mL}$ of this adjusted solution was tested. Due to interference of ascorbic acid, citric acid, nitrite and uric acid [52, 53], the modified electrode covered with a thin film of nafion is used for CySH detection in real samples. Nafion film is a cation exchange polymer and repels ascorbic acid and other negatively charged species at optimized conditions [54]. The standard addition method was used for simple evaluation of $\mathrm{CySH}$ in serum sample. The concentration of $\mathrm{CySH}$ in serum sample is found to be $200.5-269.6 \mu \mathrm{M}$, which is a normal dosage for $\mathrm{CySH}$ in serum samples $[55,56]$. Table 2 shows the results obtained for $\mathrm{CySH}$ content of the real samples. It is obvious that the obtained recovery rates are in the range of 97.5-101.5\%. Therefore, the modified proposed sensor can be used for CySH detection in real samples.

\section{Conclusions}

A new composite material modified electrode as $\mathrm{Au} /$ AuNPs/PNA/ZnSe-QD/ACA was prepared by

Table 1 Electrochemical response for L-cysteine using various modified electrodes

\begin{tabular}{|c|c|c|c|}
\hline Electrode & Linear range $(\mu \mathrm{M})$ & $\operatorname{LoD}(\mu \mathrm{M})$ & Ref. \\
\hline Electrospun carbon nanofibers modified CPE & $0.15-63.8$ & 0.10 & [43] \\
\hline PolyN,Ndimethylaniline/ferrocyanide film/CPE & $7.40-138$ & 6.38 & [44] \\
\hline Ordered mesoporous carbon & $3.00-130$ & 0.10 & [45] \\
\hline Lead ruthenate pyrochlore modified electrode & Up to 560 & 1.70 & [46] \\
\hline Cobalt(II) salophen-modified CPE & $2.00-10000$ & 1.00 & [47] \\
\hline $\mathrm{Ru}[($ tpy $)(\mathrm{bpy}) \mathrm{Cl}] \mathrm{PF} 6 /$ sol-gel CCE & $5.00-685$ & 1.00 & [48] \\
\hline MWCNTs-modified GCE & $10.0-500$ & 5.40 & [49] \\
\hline $\mathrm{Au}-\mathrm{SH}-\mathrm{SiO}_{2} @ \mathrm{Cu}-\mathrm{MOF}$ & $0.02-300$ & 0.008 & [25] \\
\hline Poly-3,4-hylenedioxythiophene/screen-printed electrode & $0.05-200$ & 0.03 & [50] \\
\hline Copper-cobalt hexacyanoferrate/ CPE & $6.00-1000$ & 5.00 & [51] \\
\hline This work & $1-11.0$ & 0.04 & \\
\hline
\end{tabular}

$C P E$ carbon paste electrode, $G C E$ glassy carbon electrode, $C C E$ carbon ceramic electrode, $M O F$ metal-organic framework 
electrodepositing of ACA on the surface of PNA/ZnSe-QD AuNP Au electrode. Compared with Au/AuNPs/ACA, Au/ $\mathrm{PNA} / \mathrm{ZnSe}-\mathrm{QD} / \mathrm{ACA}$ and $\mathrm{Au} / \mathrm{ACA}$, combination of $\mathrm{ZnSe}-$ QD and AuNPs resulted in improvement of both the reversibility and current responses of Au/AuNPs/PNA/ $\mathrm{ZnSe}-\mathrm{QD} / \mathrm{ACA}$ electrode. The Au/AuNPs/PNA/ZnSe-QD/ ACA electrode also enhanced electrocatalytic activity toward oxidation of $\mathrm{CySH}$. It was also found that the peak potential for oxidation of $\mathrm{CySH}$ was significantly shifted to a more negative potential $(0.05 \mathrm{~V}$ vs. $\mathrm{Agl} \mathrm{AgCl})$ compared to that of the Au/AuNPs/PNA/ZnSe-QD modified electrode $(0.55 \mathrm{~V}$ vs. $\mathrm{Ag} \mid \mathrm{AgCl})$. Some kinetic parameters, such as the electron transfer coefficient, the diffusion coefficient of $\mathrm{CySH}$ and the catalytic rate constant $k_{\text {cat }}$ of the catalytic reaction were calculated. A sensitive amperometric method was proposed for determination of $\mathrm{CySH}$ with the advantages of fast response and good reproducibility.

Acknowledgments The authors gratefully acknowledge the support of this work by the Khorramabad Branch, Islamic Azad University for financial support.

Open Access This article is distributed under the terms of the Creative Commons Attribution License which permits any use, distribution, and reproduction in any medium, provided the original author(s) and the source are credited.

\section{References}

1. J.C. Claussen, A.D. Franklin, A. Haque, D.M. Porterfield, T.S. Fisher, Electrochemical biosensor of nanocube-augmented carbon nanotube networks. ACS Nano 3(1), 37-44 (2009). doi:10. $1021 / \mathrm{nn} 800682 \mathrm{~m}$

2. T.G. Drummond, M.G. Hill, J.K. Barton, Electrochemical DNA sensors. Nat. Biotechnol. 21(10), 1192-1199 (2003). doi:10.1038/ nbt873

3. F. Patolsky, G. Zheng, C.M. Lieber, Nanowire sensors for medicine and the life sciences. Nanomedicine 1(1), 51-65 (2006). doi: $10.2217 / 17435889.1 .1 .51$

4. M. Hung, D.M. Stanbury, Catalytic and direct oxidation of cysteine by octacyanomolybdate(V). Inorg. Chem. 44(10), 3541-3550 (2005). doi:10.1021/ic050427c

5. T. Inoue, J.R. Kirchhoff, Electrochemical detection of thiols with a coenzyme pyrroloquinoline quinone modified electrode. Anal. Chem. 72(23), 5755-5760 (2000). doi:10.1021/ac000716c

6. M.M. Ardakani, P. Rahimi, P.E. Karami, H.R. Zare, H. Naeimi, Electrocatalytic oxidation of cysteine by quinizarine at glassy carbon electrode. Sens. Actuators B 123(2), 763-768 (2007). doi:10.1016/j.snb.2006.10.015

7. S. Shahrokhian, Lead phthalocyanine as a selective carrier for preparation of a cysteine-selective electrode. Anal. Chem. 73(24), 5972-5978 (2001). doi:10.1021/ac010541m

8. P.C. White, N.S. Lawrence, J. Davis, R.G. Compton, Electrochemically initiated 1, 4 additions: a versatile route to the determination of thiols. Anal. Chim. Acta 447(1-2), 1-10 (2001). doi:10.1016/S0003-2670(01)01297-1

9. S. Seshadri, A. Beiser, J. Selhub, P.F. Jacques, I.H. Rosenberg, R.B. D'Agostino, P.W.F.N. Wilson, P.A. Wolf, Plasma homocysteine as a risk factor for dementia and alzheimer's disease. N. Engl. J. Med. 346(7), 476-483 (2002). doi:10.1056/NEJMoa011613
10. M.A. Hofmann, B. Kohl, M.S. Zumbach, V. Borcea, A. Bierhaus, M. Henkels, J. Amiral, W. Fiehn, R. Ziegler, P. Wahl, P.P. Nawroth, Hyperhomocyst(e)inemia and endothelial dysfunction in IDDM. Diabetes Care 20(12), 1880-1886 (1997). doi:10.2337/ diacare.20.12.1880

11. E.K. Hoogeveen, P.J. Kostense, P.J. Beks, A.J.C. Mackaay, C. Jakobs, L.M. Bouter, R.J. Heine, C.D. Stehouwer, Hyper homocysteinemia is associated with an increased risk of cardiovascular disease, especially in non-insulin dependent diabetes mellitus: a population-based study. Arterioscler. Thromb. Vasc. Biol. 18(1), 133-138 (1998). doi:10.1161/01.ATV.18.1.133

12. B. Hultberg, E. Agardh, A. Andersson, L. Brattstrom, A. Isaksson, B. Israelsson, C.D. Agardh, Increased levels of plasma homocysteine are associated with nephropathy, but not severe retinopathy in type 1 diabetes mellitus. Scand. J. Clin. Lab. Inv. 51(3), 277-282 (1991). doi:10.3109/00365519109091615

13. E. Sharifi, A. Salimi, E. Shams, DNA/nickel oxide nanoparticles/ osmium(III)-complex modified electrode toward selective oxidation of L-cysteine and simultaneous detection of L-cysteine and homocysteine. Bioelectrochemistry 86(6), 9-21 (2012). doi:10. 1016/j.bioelechem.2011.12.013

14. W. Wang, O. Rusin, X. Xu, K.K. Kim, J.O. Escobedo, S.O. Fakayode, K.A. Fletcher, M. Lowry, C.M. Schowalter, C.M. Lawrence, F.R. Fronczek, I.M. Warner, R.M. Strongin, Detection of homocysteine and cysteine. J. Am. Chem. Soc. 127(45), 15949-15958 (2005)

15. G. Chwatko, E. Bald, Determination of cysteine in human plasma by high-performance liquid chromatography and ultraviolet detection after pre-column derivatization with 2-chloro-1-methylpyridinium iodide. Talanta 52(3), 509-515 (2000). doi:10.1016/ S0039-9140(00)00394-5

16. A. Sano, H. Nakamura, Chemiluminescence detection of thiols by high-performance liquid chromatography using o-Phthalaldehyde and $N$-(4-Aminobutyl)- $N$-ethylisoluminol as precolumn derivatization reagents. Anal. Sci. 14(4), 731-737 (1998). doi:10.2116/ analsci.14.731

17. K. Arlt, S. Brandt, J. Kehr, Amino acid analysis in five pooled single plant cell samples using capillary electrophoresis coupled to laser-induced fluorescence detection. J. Chromatogr. A 926(2), 319-325 (2001). doi:10.1016/S0021-9673(01)01052-4

18. M. Ummadi, B.C. Weimer, Use of capillary electrophoresis and laser-induced fluorescence for attomole detection of amino acids. J. Chromatogr. A 964(1-2), 243-253 (2002). doi:10.1016/S00219673(02)00692-1

19. F. Tanaka, N. Mase, C.F. Barbas, Determination of cysteine concentration by fluorescence increase: reaction of cysteine with a fluorogenic aldehyde. Chem. Commun. 5, 1762-1763 (2004). doi:10.1039/b405642f

20. D.A.M. Zaia, K.C.L. Ribas, C.T.B.V. Zaia, Spectrophotometric determination of cysteine and/or carbocysteine in a mixture of amino acids, shampoo, and pharmaceutical products using p-benzoquinone. Talanta 50(5), 1003-1010 (1999). doi:10.1016/ S0039-9140(99)00218-0

21. G. Shi, J. Lu, F. Xu, W. Sun, L. Jin, K. Yamamoto, S. Tao, J. Jin, Determination of glutathione in vivo by microdialysis using liquid chromatography with a cobalt hexacyanoferrate chemically modified electrode. Anal. Chim. Acta 391(4), 307-313 (1999). doi:10.1016/S0003-2670(99)00274-3

22. F. Pak, K. Meral, R. Altundaş, D. Ekinci, Self-assembled monolayers of fluorene- and nitrofluorene-terminated thiols on polycrystalline gold electrode: electrochemical and optical properties. J. Electroanal. Chem. 654(1-2), 20-28 (2011). doi:10.1016/j. jelechem.2011.01.041

23. S.M. Chen, J.Y. Chen, R. Thangamuthu, Electrochemical preparation of brilliant-blue-modified poly(diallyldimethylammoniumchloride) and nafion-coated glassy carbon electrodes and their electrocatalytic 
behavior towards oxygen and L-cysteine. Electroanalysis 20(14), 1565-1573 (2008). doi:10.1002/elan.200804213

24. S. Ge, M. Yan, J. Lu, M. Zhang, F. Yu, J. Yu, X. Song, S. Yu, Electrochemical biosensor based on graphene oxide-Au nanoclusters composites for L-cysteine analysis. Biosen. Bioelectron. 31(1), 49-54 (2012). doi:10.1016/j.bios.2011.09.038

25. H. Hosseini, H. Ahmar, A. Dehghani, A. Bagheri, A. Tadjarodi, A.R. Fakhari, A novel electrochemical sensor based on metal-organic framework for electro-catalytic oxidation of L-cysteine. Biosen. Bioelectron. 42, 426-429 (2013). doi:10.1016/j.bios.2012.09.062

26. M. Zhou, J. Ding, L.-P. Guo, Q.-K. Shang, Electrochemical behavior of L-cysteine and its detection at ordered mesoporouscarbon-modified glassy carbon electrode. Anal. Chem. 79(14), 5328-5335 (2007). doi:10.1021/ac0703707

27. M. Liu, G. Shi, L. Zhang, Y. Cheng, L. Jin, Quantum dots modified electrode and its application in electroanalysis of hemoglobin. Electrochem. Commun. 8(2), 305-310 (2006). doi:10.1016/j.elecom.2005.11.026

28. J. Drbohlavova, V. Adam, R. Kizek, J. Hubalek, Quantum dotscharacterization, preparation and usage in biological systems. Int. J. Mol. Sci. 10(2), 656-673 (2009). doi:10.3390/ijms10020656

29. J. Aldana, Y.A. Wang, X. Peng, Photochemical instability of CdSe nanocrystals coated by hydrophilic thiols. J. Am. Chem. Soc. 123(36), 8844-8850 (2001). doi:10.1021/ja016424q

30. M.J. Giz, B. Duong, N.J. Tao, In situ STM study of self-assembled mercaptopropionic acid monolayers for electrochemical detection of dopamine. J. Electroanal. Chem. 465(1), 72-79 (1999). doi:10.1016/S0022-0728(99)00056-X

31. J. Li, G. Zou, X. Hu, X. Zhang, Electrochemistry of thiol-capped CdTe quantum dots and its sensing application. J. Electroanal. Chem. 625(1), 88-91 (2009). doi:10.1016/j.jelechem.2008.10.011

32. J. Berna, M. Alajarín, R.A. Orenes, Azodicarboxamides as template binding motifs for the building of hydrogen-bonded molecular shuttles. J. Am. Chem. Soc. 132(31), 10741-10747 (2010). doi:10.1021/ja101151t

33. H. Cui, Y. Xu, Z.F. Zhang, Multichannel electrochemiluminescence of luminol in neutral and alkaline aqueous solutions on a gold nanoparticle self-assembled electrode. Anal. Chem. 76(14), 4002-4010 (2004). doi:10.1021/ac049889i

34. J.J. Andrade, J.A. Brasil Jr, P.M.A. Farias, A. Fontes, B.S. Santos, Synthesis and characterization of blue emitting $\mathrm{ZnSe}$ quantum dots. Microelectron. J. 40(3), 641-643 (2009). doi:10.1016/j. mejo.2008.06.040

35. V. Swayambunathan, D. Hayes, K.H. Schmidt, Y.X. Liao, D. Meisel, Thiol surface complexation on growing cadmium sulfide clusters. J. Am. Chem. Soc. 112(10), 3831-3837 (1990). doi:10. 1021/ja00166a017

36. M.B. Gholivand, A. Azadbakht, Fabrication of a highly sensitive glucose electrochemical sensor based on immobilization of $\mathrm{Ni}(\mathrm{II})$-pyromellitic acid and bimetallic $\mathrm{Au}-\mathrm{Pt}$ inorganic-organic hybrid nanocomposite onto carbon nanotube modified glassy carbon electrode. Electrochim. Acta 76, 300-311 (2012). doi:10. 1016/j.electacta.2012.05.037

37. S. Antoniadou, A.D. Jannakoudakis, E. Theodoridou, Electrocatalytic reactions on carbon fibre electrodes modified by hemine II. Electro-oxidation of hydrazine. Synth. Met. 30(3), 295-304 (1980). doi:10.1016/0379-6779(89)90652-8

38. E. Laviron, General expression of the linear potential sweep voltammogram in the case of diffusionless electrochemical systems. J. Electroanal. Chem. 101(1), 19-28 (1979). doi:10.1016/ S0022-0728(79)80075-3

39. A.J. Bard, L.R. Faulkner, Electrochemical Methods: Fundamentals and Applications, 2nd edn. (Wiley, New York, 2000)

40. J.A. Harrison, Z.A. Khan, The oxidation of hydrazine on platinum in acid solution. J. Electroanal. Chem. 28(1), 131-138 (1970). doi:10.1016/S0022-0728(70)80288-1
41. T.R. Ralph, M.L. Hitchman, J.P. Millington, F.C. Walsh, The electrochemistry of 1-cystine and 1-cysteine: part 1: Thermodynamic and kinetic studies. J. Electroanal. Chem. 375(1-2), 1-15 (1994). doi:10.1016/0022-0728(94)03407-9

42. Z. Galus, Fundamentals of Electrochemical Analysis (Horwood, New York, 1976)

43. X. Tang, Y. Liu, H. Hou, T. You, Electrochemical determination of L-Tryptophan, L-Tyrosine and L-Cysteine using electrospun carbon nanofibers modified electrode. Talanta 80(5), 2182-2186 (2010). doi:10.1016/j.talanta.2009.11.027

44. R. Ojani, J.B. Raoof, E. Zarei, Preparation of poly $N$, $N$-dimethylaniline/ferrocyanide film modified carbon paste electrode: application to electrocatalytic oxidation of L-cysteine. J. Electroanal. Chem. 638(2), 241-245 (2010). doi:10.1016/j.jelechem. 2009.11.005

45. J.C. Ndamanisha, J. Bai, B. Qi, L. Guo, Application of electrochemical properties of ordered mesoporous carbon to the determination of glutathione and cysteine. Anal. Biochem. 386(1), 79-84 (2009). doi:10.1016/j.ab.2008.11.041

46. J.M. Zen, A.S. Kumar, J.-C. Chen, Electrocatalytic oxidation and sensitive detection of cysteine on a lead ruthenate pyrochlore modified electrode. Anal. Chem. 73(6), 1169-1175 (2001). doi:10.1021/ac0010781

47. M.K. Amini, J.H. Khorasani, S.S. Khaloo, S. Tangestaninejad, Cobalt(II) salophen-modified carbon-paste electrode for potentiometric and voltammetric determination of cysteine. Anal. Biochem. 320(1), 32-38 (2003). doi:10.1016/S0003-2697(03)00355-5

48. A. Salimi, S. Pourbeyram, Renewable sol-gel carbon ceramic electrodes modified with a Ru-complex for the amperometric detection of L-cysteine and glutathione. Talanta 60(1), 205-214 (2003). doi:10.1016/S0039-9140(03)00125-5

49. A. Salimi, R. Hallaj, Catalytic oxidation of thiols at preheated glassy carbon electrode modified with abrasive immobilization of multiwall carbon nanotubes: applications to amperometric detection of thiocytosine, L-cysteine and glutathione. Talanta 66(4), 967-975 (2005). doi:10.1016/j.talanta.2004.12.040

50. W.Y. Su, S.H. Cheng, Electrocatalysis and sensitive determination of cysteine at poly(3,4-ethylenedioxythiophene)-modified screen-printed electrodes. Electrochem. Commun. 10(6), 899-902 (2008). doi:10.1016/j.elecom.2008.04.013

51. A. Abbaspour, A. Ghaffarinejad, Electrocatalytic oxidation of Lcysteine with a stable copper-cobalt hexacyanoferrate electrochemically modified carbon paste electrode. Electrochim. Acta 53(22), 6643-6650 (2008). doi:10.1016/j.electacta.2008.04.065

52. Y.P. Dong, L. Pei, X.F. Chu, W.B. Zhang, Q.F. Zhang, Electrochemical behavior of cysteine at a $\mathrm{CuGeO}_{3}$ nanowires modified glassy carbon electrode. Electrochim. Acta 55(18), 5135-5141 (2010). doi:10.1016/j.electacta.2010.04.020

53. P. Sweth, A.S. Kumar, Phosphomolybdic acid nano-aggregates immobilized nafion membrane modified electrode for selective cysteine electrocatalytic oxidation and anti-dermatophytic activity. Electrochim. Acta 98, 54-65 (2013). doi:10.1016/j.electacta. 2013.03.023

54. H. Razmi, A. Azadbakht, Electrochemical characteristics of dopamine oxidation at palladium hexacyanoferrate film, electroless plated on aluminum electrode. Electrochim. Acta 50(11), 2193-2201 (2005). doi:10.1016/j.electacta.2004.10.001

55. A.A. Ensafi, S. Behyan, Sensing of L-cysteine at glassy carbon electrode using nile blue A as a mediator. Sens. Actuators B 122(1), 282-288 (2007). doi:10.1016/j.snb.2006.05.035

56. S.P. Stabler, P.D. Marcell, E.R. Podell, R.H. Allen, Quantitation of total homocysteine, total cysteine, and methionine in normal serum and urine using capillary gas chromatography-mass spectrometry. Anal. Biochem. 162(1), 185-196 (1987). doi:10.1016/ 0003-2697(87)90026-1 